University of Wollongong

Research Online

Australian Institute for Innovative Materials -

Papers

Australian Institute for Innovative Materials

$1-1-2017$

Origin of Photoelectrochemical Generation of Dihydrogen by a DyeSensitized Photocathode without an Intentionally Introduced Catalyst

Dijon A. Hoogeveen

Monash University

Maxime Fournier

Monash University

Shannon A. Bonke

Monash University

Andrew Nattestad

University of Wollongong, anattest@uow.edu.au

Amaresh Mishra

University of Ulm, amaresh.mishra@uni-ulm.de

See next page for additional authors

Follow this and additional works at: https://ro.uow.edu.au/aiimpapers

Part of the Engineering Commons, and the Physical Sciences and Mathematics Commons

Research Online is the open access institutional repository for the University of Wollongong. For further information contact the UOW Library: research-pubs@uow.edu.au 


\title{
Origin of Photoelectrochemical Generation of Dihydrogen by a Dye-Sensitized Photocathode without an Intentionally Introduced Catalyst
}

\begin{abstract}
Dye-sensitized photocathodes have been observed on several occasions to sustain light-driven $\mathrm{H} 2$ generation without intentionally introduced catalysts. Herein, plausible mechanisms addressing this phenomenon are probed by a combination of long-term photoelectrochemical measurements with concurrent gas chromatography, transient absorption spectroscopy, and inductively coupled mass spectrometry using a perylenemonoimide-sexithiophene-triphenylamine (PMI-6T-TPA) sensitized NiO electrode. The experimental evidence obtained discounts the possibility for direct reduction of hydrogen by the dye and demonstrates that the availability of interfaces between dye molecules and any electrically disconnected $\mathrm{NiO}$ particles exposed to the electrolyte solution is critical for photoelectrocatalytic $\mathrm{H} 2$ generation. These interfaces are postulated to serve as photoactive sites for the formation of a hydrogen evolution catalyst, e.g., metallic nickel, which can accept photogenerated electrons from the excited dye molecules. The Ni 0 catalyst can form via photoelectroreduction of $\mathrm{Ni} 2+$, which has been found to slowly dissolve from the NiO support into the solutions during the photoelectrochemical measurements.

Additionally, dependence of the $\mathrm{H} 2$ generation rate on the anion within the electrolyte has been identified, with the highest rates of 35-40 nmol h $-1 \mathrm{~cm}-2$ achieved with acetate. The origin of this dependence remains unsolved at this stage but is clearly demonstrated to be not associated with the different rates of dissolution of $\mathrm{NiO}$, the presence of other transition metal contaminants, nor electronic impacts of the anion on the $\mathrm{NiO}$ valence band. Overall, the results herein demonstrate that the effects of the chemical nature of the electrolyte, metallic nickel deposited from dissolved $\mathrm{Ni} 2+$, and availability of the interfaces between disconnected $\mathrm{NiO}$ and adsorbed dye should be considered when interpreting the photoelectrocatalytic performance of dye-sensitized photocathodes for dihydrogen evolution.

Disciplines

Engineering | Physical Sciences and Mathematics

\section{Publication Details}

Hoogeveen, D., Fournier, M., Bonke, S. A., Nattestad, A., Mishra, A., Bäuerle, P., Spiccia, L., Mozer, A. J. \& Simonov, A. N. (2017). Origin of Photoelectrochemical Generation of Dihydrogen by a Dye-Sensitized Photocathode without an Intentionally Introduced Catalyst. The Journal of Physical Chemistry C: Energy Conversion and Storage, Optical and Electronic Devices, Interfaces, Nanomaterials, and Hard Matter, 121 (46), 25836-25846.
\end{abstract}

\section{Authors}

Dijon A. Hoogeveen, Maxime Fournier, Shannon A. Bonke, Andrew Nattestad, Amaresh Mishra, Peter Bauerle, Leone Spiccia, Attila J. Mozer, and Alexandr N. Simonov 


\section{The Origin of Photo-Electrochemical Generation of}

\section{Dihydrogen by a Dye-Sensitized Photocathode}

\section{without an Intentionally-Introduced Catalyst}

Dijon A. Hoogeveen,$^{\dagger}$ Maxime Fournier, ${ }^{\dagger}$ Shannon A. Bonke,$^{\dagger, \S}$ Amaresh Mishra, ${ }^{\ddagger, \perp}$

Peter Bäuerle,$^{\dagger}$ Leone Spiccia,$^{\dagger \rtimes}$ Attila J. Mozer, ${ }^{\Delta}$ and Alexandr N. Simonov ${ }^{\dagger *}$

$\dagger$ School of Chemistry and ARC Centre of Excellence for Electromaterials Science, Monash

University, Victoria 3800, Australia;

E-mail: alexandr.simonov@monash.edu Telephone: +61 399050395

$\S$ Institut Nanospektroskopie, Helmholtz-Zentrum Berlin für Materialien und Energie,

Kekuléstraße 5, 12489 Berlin, Germany

ॠnstitut für Organische Chemie II und Neue Materialien, Universität Ulm, Albert-Einstein-

Allee 11, 89081 Ulm, Germany

${ }^{\perp}$ School of Chemistry, Sambalpur University, Jyoti Vihar-768019, Sambalpur, India

${ }^{\Delta}$ Intelligent Polymer Research Institute and ARC Centre of Excellence for Electromaterials

Science, University of Wollongong, Wollongong, 2522, Australia

${ }^{\times}$Our colleague, mentor and friend Prof. Leone Spiccia has passed away before this work could be published. Leone was an outstanding researcher and personality, and is sadly missed. 


\section{ABSTRACT}

Dye-sensitized photocathodes have been observed on several occasions to sustain light-driven $\mathrm{H}_{2}$ generation without intentionally-introduced catalysts. Herein, plausible mechanisms addressing this phenomenon are probed by a combination of long-term photo-electrochemical measurements with concurrent gas chromatography, transient absorption spectroscopy and inductively coupled mass spectrometry using a perelenmonoimid-sexithiophene-triphenylamine (PMI-6T-TPA) sensitized $\mathrm{NiO}$ electrode. The experimental evidence obtained discounts the possibility for direct reduction of hydrogen by the dye and demonstrates that the availability of interfaces between dye molecules and any electrically-disconnected $\mathrm{NiO}$ particles exposed to the electrolyte solution is critical for photo-electrocatalytic $\mathrm{H}_{2}$ generation. These interfaces are postulated to serve as photo-active sites for the formation of a hydrogen evolution catalyst, e.g. metallic nickel, which can accept photo-generated electrons from the excited dye molecules. The $\mathrm{Ni}^{0}$ catalyst can form via photo-electroreduction of $\mathrm{Ni}^{2+}$, which has been found to slowly dissolve from the $\mathrm{NiO}$ support into the solutions during the photo-electrochemical measurements. Additionally, dependence of the $\mathrm{H}_{2}$ generation rate on the anion within the electrolyte has been identified, with the highest rates of 35-40 $\mathrm{nmol} \mathrm{h}-1 \mathrm{~cm}^{-2}$ achieved with acetate. The origin of this dependence remains unsolved at this stage, but is clearly demonstrated to be not associated with the different rates of dissolution of $\mathrm{NiO}$, the presence of other transition metal contaminants, nor electronic impacts of the anion on the $\mathrm{NiO}$ valence band. Overall, the results herein demonstrate that the effects of the chemical nature of the electrolyte, metallic nickel deposited from dissolved $\mathrm{Ni}^{2+}$, and availability of the interfaces between disconnected $\mathrm{NiO}$ and adsorbed dye should be considered when interpreting the photo-electrocatalytic performance of dye-sensitized photocathodes for dihydrogen evolution. 


\section{INTRODUCTION}

Artificial photosynthesis, as a renewable alternative to fossil fuel extraction, is a notion that continues to motivate researchers since it was first popularized over a century ago. ${ }^{1-3}$ Based conceptually on existing biogenic photosynthesis, this process involves the use of energy from solar irradiation to drive both the water oxidation reaction (equation 1), and a fuel-forming reduction process. The most facile fuel-forming process is the hydrogen evolution reaction (HER, equation 2). ${ }^{4}$

$$
\begin{array}{ll}
2 \mathrm{H}_{2} \mathrm{O} \rightleftharpoons \mathrm{O}_{2}+4 \mathrm{H}^{+}+4 \mathrm{e}^{-} & \begin{array}{l}
E^{0}=1.23 \mathrm{~V} \text { vs. RHE } \\
\text { (RHE is reversible hydrogen electrode) }
\end{array} \\
2 \mathrm{H}^{+}+2 \mathrm{e}^{-} \rightleftharpoons \mathrm{H}_{2} & E^{0}=0.00 \mathrm{~V} v \text { s. RHE } \\
2 \mathrm{H}_{2} \mathrm{O} \rightleftharpoons 2 \mathrm{H}_{2}+\mathrm{O}_{2} & \Delta E=1.23 \mathrm{~V}
\end{array}
$$

Dye-Sensitized Photo-Electrochemical Cells $\left(\right.$ DSPECs) ${ }^{5}$ are a device architecture for $\mathrm{H}_{2}$ generation by light-driven water splitting that has seen an increasing interest amongst researchers as evidenced by the number of new publications in the field ( $\mathrm{see}^{6-8}$ and references therein). Built upon many years of research into Dye-Sensitized Solar Cells (DSSCs), they also involve the sensitization of mesoporous wide-band gap semiconductors with light-absorbing dyes. DSPECs differ from DSSCs in that the photo-generated charges from the photo-excited dye oxidize/reduce $\mathrm{H}_{2} \mathrm{O}$ rather than a reversible redox mediator. All published single electrode systems require the application of external potential to carry out the overall water splitting reaction. ${ }^{69}$ Instead, a tandem configuration involving a DS photocathode and photoanode can provide a sufficient driving force to decompose water into $\mathrm{H}_{2}$ and $\mathrm{O}_{2}$, ideally using $p$-type and $n$ type dyes absorbing at complementary wavelengths of the solar spectrum. Optimization of this non-trivial, multi-component device requires studies on individual photoelectrodes, which are 
achieved by substituting the input from the opposite electrode with an applied potential in a standard three-electrode setup. The best hitherto reported photoanodes perform at a substantially higher level than their photocathode counterparts, thus driving strong research interest in photocathode development as the best way to boost overall tandem device performance.

Upon illumination of a typical DS photocathode, $p$-type dye molecules adsorbed onto a $p$-type wide bandgap semiconductor (e.g. NiO) undergo photo-excitation (equation 4), followed by charge injection/separation on a typically sub-nanosecond timescale (equation 5). ${ }^{10-13}$ The generated dye anion can transfer an electron to an oxidized species in solution such as a redox mediator in a DSSC (equation 6a), or to a nearby electrocatalyst in a DSPEC (equation 6b). In the latter case, the electrocatalyst provides a low-energy-barrier pathway for the two electron, two proton $\mathrm{H}_{2}$ evolution reaction (equation 2) ${ }^{14}$ In addition to its efficiency for the HER, the physical integration of the catalyst on the surface of the electrode should be in a manner that allows for all the dye molecules to be close enough to promote effective electron transfer between the two with efficient charge transport within the dye layer also highly desirable. In reality, the combination of this electron transfer step and the multi-electron catalytic reaction struggles to keep pace with the fast single-electron photochemistry of the dyes. This results in a kinetic mismatch that produces very significant energy losses in the DSPEC electrodes via charge recombination (shown in equation $6 \mathrm{c}$ for photocathodes). ${ }^{6}$

$$
\begin{aligned}
& \text { Dye- } \mathrm{NiO}+h v \rightarrow \text { Dye }^{*}-\mathrm{NiO} \\
& \text { Dye }-\mathrm{NiO} \rightarrow \mathrm{Dye}^{(-)}-\mathrm{NiO}^{(+)} \\
& \text {Dye }^{(-)}-\mathrm{NiO}^{(+)}+\mathrm{X} \rightarrow \text { Dye- }-\mathrm{NiO}^{(+)}+\mathrm{X}^{-}
\end{aligned}
$$




$$
\begin{aligned}
& \text { Dye }^{(-)}-\mathrm{NiO}^{(+)}+\text {Cat } \rightarrow \text { Dye-NiO }+\mathrm{Cat}^{(-)} \\
& \text {Dye }^{(-)}-\mathrm{NiO}^{(+)} \rightarrow \text { Dye-NiO }
\end{aligned}
$$

A number of $\mathrm{H}_{2}$ evolution catalysts for DSPECs have been demonstrated to date, as well as methods for their integration into photocathodes. Molecular systems ${ }^{15}$ have commonly been employed and immobilized along with the dye on the semiconductor surface through dropcasting, ${ }^{16}$ co-adsorption, ${ }^{17,18}$ covalent attachment, ${ }^{19,20}$ or ionic interactions. ${ }^{21,22}$ The catalyst was also designed to remain dissolved in solution in some cases. ${ }^{12,23}$ These approaches generally allow for a good dispersion of catalytic sites amongst the dye molecules, but both their catalytic activity and stability are major ongoing challenges. Heterogeneous solid-state catalysts are more active and robust than molecular ones, though approaches based on their use in DSPEC electrodes are rarely reported and less well studied, presumably due to difficulties in establishing efficient electron-transfer pathways in this configuration. Nevertheless, we have recently demonstrated very promising performance of a DSPEC photocathode modified with the state-ofthe-art $\mathrm{H}_{2}$ evolution electrocatalyst, viz. metallic platinum. ${ }^{24}$ Furthermore, iridium oxide particles have been successfully incorporated in DS photoanodes for significantly improved water photoelectrooxidation. $^{25}$

Interestingly, $\mathrm{H}_{2}$ generation has been observed on $p$-type $\mathrm{DS}$ mesoporous $\mathrm{NiO}$ electrodes without the addition of any intended catalysts, under various conditions in four independent publications, though at comparatively low rates in all cases. In 2012, Tong et al. ${ }^{26}$ were the first to report on $\mathrm{H}_{2}$ evolution provided by the perelenmonoimid-sexithiophene-triphenylamine dye (PMI-6T-TPA) adsorbed on a $1.8 \mu \mathrm{m}$ thick, $2 \mathrm{~cm}^{2}$ area photocathode. Photo-electrocatalytic $\mathrm{H}_{2}$ generation at a rate $\left(\omega_{\mathrm{H} 2}\right)$ of $c a 80 \mathrm{nmol}$ hour ${ }^{-1} \mathrm{~cm}^{-2}$ was achieved with this photocathode in 
$0.1 \mathrm{M}$ aqueous sodium sulfate $(\mathrm{pH} 7.0)$ at an applied potential of $0.197 \mathrm{~V}$ vs. normal hydrogen electrode (NHE) (0.61 V vs. RHE) and under $600-800 \mathrm{~mW} \mathrm{~cm}^{-2}$ illumination from a Xe light source. Separately, Kamire et al. ${ }^{12}$ used a perylene-3,4-dicarbox-imide dye on a $1 \mu \mathrm{m}$ thick, $0.36 \mathrm{~cm}^{2}$ area photocathode that was additionally insulated by atomic layer deposited $\mathrm{Al}_{2} \mathrm{O}_{3}$ to demonstrate $\mathrm{H}_{2}$ evolution at rates of $c a 30 \mathrm{nmol} \mathrm{hour}{ }^{-1} \mathrm{~cm}^{-2}$. Therein, $0.1 \mathrm{M} \mathrm{Na}_{2} \mathrm{SO}_{4}+\mathrm{H}_{2} \mathrm{SO}_{4}$ in an acetonitrile : water (1:1 vol.) mixed solvent was used as an electrolyte solution, while irradiation was provided by a white light emitting diode $\left(200 \mathrm{~mW} \mathrm{~cm}{ }^{-2} ; \lambda>420 \mathrm{~nm}\right)$, with an applied potential of $-0.19 \mathrm{~V} v s$. NHE (undefinable $v s$. RHE due to uncertain $\mathrm{pH}$ ). Antila et al. ${ }^{18}$ have also detected trace $\mathrm{H}_{2}$ during experiments with coumarin 343 dye on a $1.0 \mu \mathrm{m}$ thick, $1.0 \mathrm{~cm}^{2}$ area photocathode. Finally, we have previously reported on the capacity of PMI-6TTPA-based photocathodes $\left(2 \mu \mathrm{m}\right.$ thick, $\left.2 \mathrm{~cm}^{2}\right)$ to produce molecular hydrogen at $\omega_{\mathrm{H} 2} \approx 5 \mathrm{nmol}$ hour ${ }^{-1} \mathrm{~cm}^{-2}$ in $1.0 \mathrm{M}$ phosphate buffer $(\mathrm{pH} 7.0)$ at $0.00 \mathrm{~V}$ vs. NHE $(0.39 \mathrm{~V} v s$. RHE) under $100 \mathrm{~mW} \mathrm{~cm}^{-2}$ irradiation provided by a Xe light source (AM1.5G spectrum, $\lambda>400 \mathrm{~nm}$ ) (hereinafter, 1 sun). ${ }^{24}$

The origin of $\mathrm{H}_{2}$ evolution by the DS photocathodes reported in the aforementioned publications has been barely explored to date, although it might have important implications for DS photocathodes that are intentionally-functionalized with a HER catalyst. The present study aims to provide further insights into this phenomenon. Among other possibilities, we consider three mechanisms summarized in Scheme 1 as the most plausible pathways towards the photoelectrochemical generation of molecular hydrogen by $\mathrm{NiO}$ electrodes sensitized with a $p$-type dye. Theoretically, the photo-potential provided by the dye anion is sufficiently negative, e.g. $-0.70 \mathrm{~V} v s$. NHE for PMI-6T-TPA, ${ }^{27,28}$ which corresponds to $0.60-0.48 \mathrm{~V}$ overpotential for the HER at $\mathrm{pH} 2-4$, and, as such, can be expected to sustain observable rates of $\mathrm{H}_{2}$ generation. 

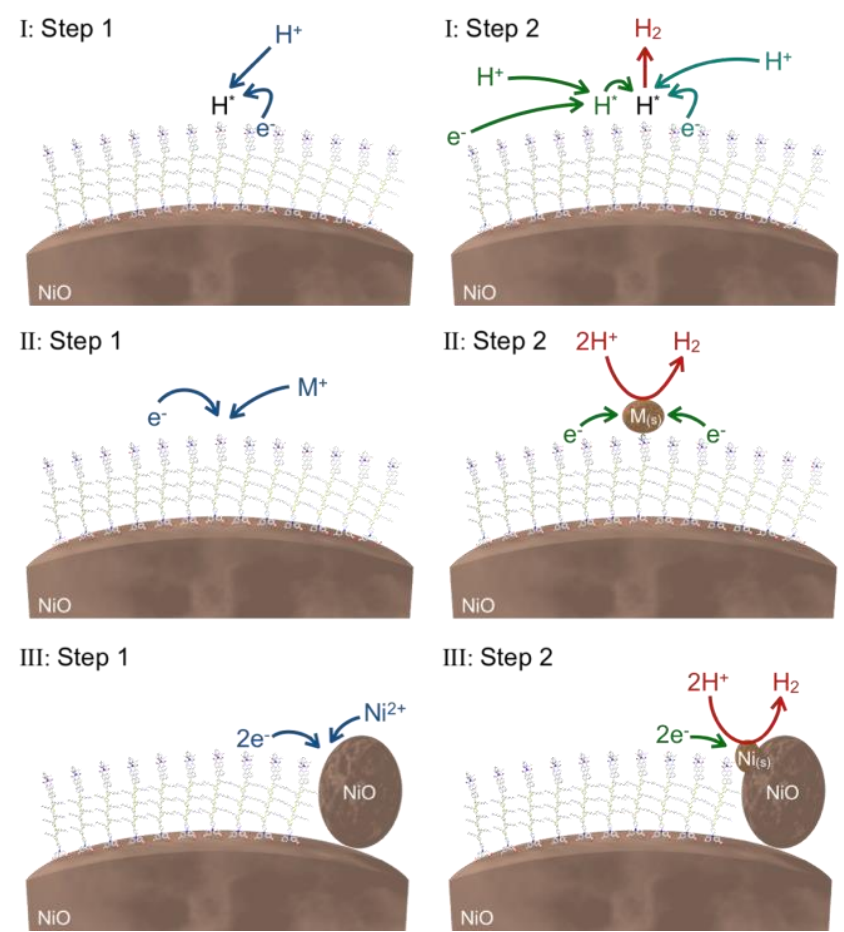

III: Step 2

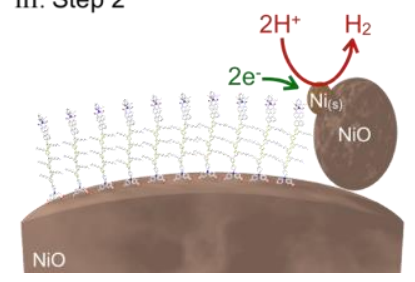

Scheme 1. Hypothetical mechanisms for photo-electrochemical $\mathrm{H}_{2}$ evolution by a DS $\mathrm{NiO}$ cathode. I: dye-monolayer surface sustains the reaction via classical Volmer-Tafel or VolmerHeyrovsky schemes. II: adventitious metal cations from solution are photo-electroreduced to produce heterogeneous $\mathrm{H}_{2}$ evolution catalysts on the DS surface. III: interfaces between dye molecules and loose, electrically disconnected $\mathrm{NiO}$ particles serve as active sites, where an electrocatalyst is formed via reduction of either $\mathrm{Ni}^{2+}$ or adventitious admixtures from solution.

In mechanism I, the dye monolayer is hypothesized to sustain $\mathrm{H}-\mathrm{H}$ bond formation via classical Volmer-Heyrovsky or Volmer-Tafel schemes. ${ }^{29}$ In a Volmer step, $\mathrm{H}^{+}$from solution is reduced to $\mathrm{H}^{*}$ by a photo-generated electron on the dye surface. In a subsequent Heyrovsky step (Scheme 1: mechanism I, teal), a second photo-generation event, involving a second $\mathrm{H}^{+}$, leads to the formation of $\mathrm{H}_{2}$. Alternatively, in a Tafel step (Scheme 1: mechanism I, green), two $\mathrm{H}^{\bullet}$ species on neighboring dye molecules combine to produce molecular hydrogen. Dye reduction 
can occur either through direct photo-excitation, or indirectly elsewhere in the monolayer followed by lateral transport of the electron, which is not uncommon for DS electrodes. ${ }^{30,31}$

In mechanism II, metal particulates formed at the photo-active sites on the DS cathode surface via (photo-)electroreduction of adventitious metal cations in solution serve as electrocatalysts for $\mathrm{H}_{2}$ evolution. The feasibility of this has been recently demonstrated for a PMI-6T-TPAsensitized $\mathrm{NiO}$ electrode intentionally-modified with electrodeposited $\mathrm{Pt}^{24}$ It has furthermore been shown in studies on cobalt and nickel complexes that were initially designed to function as molecular HER catalysts for electrochemical $\mathrm{H}_{2}$ evolution, but were eventually proven to produce metallic electrodeposits that were responsible for the observed catalysis. ${ }^{32-37}$ The level of contamination in solutions that can be encountered in an electrochemical experiment is sometimes sufficient to produce electrodeposited catalytic species. ${ }^{38,39}$

The central feature of mechanism III is the role of interfaces between dye molecules and loose, dye-free $\mathrm{NiO}$ particles within the mesoporous film that have poor electrical contact to the surrounding film (Scheme 1). Although no direct evidence exists, it is entirely possible that after the screen printing and subsequent sintering process, a number of $\mathrm{NiO}$ particles are not fully fused together. The resultant poor electrical connection to the surrounding semiconductor allows them to function independently without photo-generated holes to re-oxidise any reduced species. If they are close to photo-generated dye anions, the surfaces of these unfused $\mathrm{NiO}$ particles could either be reduced to nickel metal or serve as sites for the deposition of species as in mechanism II (Scheme 1). Regarding the former case, metallic nickel has long been known as a reasonably efficient catalyst for the hydrogen evolution reaction. ${ }^{40-43}$

Herein, the photo-electro-generation of $\mathrm{H}_{2}$ by PMA-6T-TPA-sensitized NiO photocathodes without intentionally-introduced HER catalysts is examined under a range of varying conditions 
to distinguish between the above possible mechanisms. The effects of $\mathrm{pH}$, chemical nature of electrolyte, presence of admixtures in solutions, and the availability of the interfaces between unmodified, electrically disconnected $\mathrm{NiO}$ and adsorbed dye are examined.

\section{EXPERIMENTAL SECTION}

Materials. Reagent or analytical grade chemicals were used as received from commercial suppliers. Milli-Q water (resistivity $18.2 \mathrm{M} \Omega \mathrm{cm}$ at $25{ }^{\circ} \mathrm{C}$ ) was used to prepare all aqueous solutions. Fluorine-doped $\mathrm{SnO}_{2}$ (FTO) coated glass with a sheet resistance of $8 \Omega$ square ${ }^{-1}$ was purchased from Dyesol (TEC8 Glass Plates). NiO particle powder (mean size 20 nm; 73.22 wt.\% Ni) was used as received from Inframat. The PMI-6T-TPA dye was synthesized following a published procedure. ${ }^{31}$ Buffers and $\mathrm{pH}$-adjusted solutions were prepared by alkalization of aqueous acid solutions and measured by a calibrated $\mathrm{pH}$ meter (metrohm $\mathrm{pH}$ Lab 827).

Photocathode Preparation. Procedures for the deposition of the NiO layer and its sensitization with the PMI-6T-TPA dye were conducted similarly to our previous work. ${ }^{24} \mathrm{~A}$ NiO paste (\# 1) was prepared by mixing $\mathrm{NiO}$, ethyl cellulose (5 wt.\% in ethanol) and terpineol in the ratio $4: 23: 23$ (wt.), followed by ball milling at $400 \mathrm{rpm}$ for 4 hours (Fritsch Pulverisette 7; $50 \mathrm{~mL}$ zirconia cylinder; zirconia balls of 11, 7, 5 and $3 \mathrm{~mm}$ diameter). An alternative film (\# 2) was prepared with a ratio of $4: 34.5: 23$ (wt.). Circular $\mathrm{NiO}$ films with a geometric area of $1 \mathrm{~cm}^{2}$ on FTO were printed with paste \#1 using a commercial semi-automatic screen printer (Keywell). Two successive printing cycles were performed to give a film thickness of $c a 2.0 \mu \mathrm{m}$ as measured using a Veeco Dektak 6M stylus profilometer. Electrodes were sintered in air for $30 \mathrm{~min}$ at $450{ }^{\circ} \mathrm{C}$ and for $15 \mathrm{~min}$ at $500{ }^{\circ} \mathrm{C}$. For optimization studies, square films of $0.16 \mathrm{~cm}^{2}$ were printed on laser-engraved FTO electrodes. Films of paste \#1 were printed with 2 and 3 layers (ca 2.0 and $3.0 \mu \mathrm{m}$ thick, respectively) while films of paste \# 2 were printed with 1, 2 and 
3 layers ( $c a 1.0,1.5$ and $2.1 \mu \mathrm{m}$ thick, respectively). Prior to sensitization, the $\mathrm{NiO}$ films were resintered at $450{ }^{\circ} \mathrm{C}$ for $30 \mathrm{~min}$ in air before being immersed while warm $\left(\mathrm{ca} 60{ }^{\circ} \mathrm{C}\right)$ into a $0.20 \mathrm{mM}$ PMI-6T-TPA in N,N-dimethylformamide (DMF) and left overnight $(15-20 \mathrm{~h})$ at ambient temperature $\left(\mathrm{ca} 24^{\circ} \mathrm{C}\right)$. Following sensitization, the films were soaked in fresh DMF for 10 mins to remove any unattached dye and dried under gentle air flow. Electrical contact to the electrodes was provided by soldering an aluminum wire onto part of the FTO surface. This connection and all remaining areas of the FTO surface were masked using a neutral (noncorrosive) cure silicone sealant (Selleys). Prior to all measurements, the hydrophobic photocathodes were wetted with an isopropanol : water solution (1:1 vol.), which was followed by thorough rinsing with Milli-Q water. Dye loading on selected electrodes was reduced through immersion in $0.01 \mathrm{M} \mathrm{NaOH}$ in an ethanol : dichloromethane solution (1: 1 vol.) for 10 minutes. Relative dye-loading percentage was calculated using the absorption spectra as measured by a Varian Cary 300 UV-Vis spectrophotometer on solutions where dyed films had been immersed for 16 hours for complete dye desorption.

Photo-electrochemical measurements. All photo-electrochemical experiments were performed with a Bio-Logic VSP electrochemical workstation using a three electrode setup under a high-purity Ar atmosphere (99.999\%; $\mathrm{O}_{2} \leq 2$ ppm). A $\mathrm{Ag}|\mathrm{AgCl}| \mathrm{KCl}$ (sat.) reference electrode $(C H I)$ was used in all measurements, but potentials are reported versus NHE and RHE according to relationships $E$ vs. $\mathrm{NHE}=E$ vs. $\mathrm{Ag}|\mathrm{AgCl}| \mathrm{KCl}($ sat. $)+0.197$, and $E v s . \mathrm{RHE}=E v s$. $\mathrm{Ag}|\mathrm{AgCl}| \mathrm{KCl}($ sat. $)+0.197-0.059 \mathrm{pH}$. Measurements were conducted in a custom-made photoelectrochemical cell (PEEK and PTFE body) with a quartz window using a Ni counter electrode confined to a compartment separated by a Nafion membrane. Optimization studies were conducted in a separate custom-made photo-electrochemical cell (polyurethane body) with a 
borosilicate glass window with a Pt counter electrode in a $0.1 \mathrm{M}$ borate buffer $(\mathrm{pH} 9.2)$ with 0.1 $\mathrm{M}\left[\mathrm{Co}(\text { ethylenediamine) })_{3}\right] \mathrm{Cl}_{3}$ as an electron acceptor. A solar simulator (Newport, Model 67005) equipped with a $150 \mathrm{~W}$ Xenon lamp with a spectral distribution of AM1.5G and intensity of 1 sun $\left(100 \mathrm{~mW} \mathrm{~cm}^{-2}\right)$ was used as the irradiation source. This source was calibrated by placing a reference solar cell (Frauenhofer ISE, CalLab; serial No. 010-2010, calibration mark: 10102010014ISE0311) in the light beam and adjusting neutral density filters to reach the stated current-voltage profile and efficiency. Subsequently, a $400 \mathrm{~nm}$ band pass filter was positioned to limit the irradiation to the visible range, which was needed to prevent direct band gap excitation of $\mathrm{NiO} .{ }^{45,65}$ All working electrodes were irradiated from the back side (dye- and NiO-free).

Gas Chromatography analysis. Analysis of $\mathrm{H}_{2}$ evolved during chronoamperometric experiments was undertaken with a Perkin-Elmer Clarus 580 gas chromatograph (GC) equipped with a molecular sieve $13 \mathrm{X}$ column $45-60$ mesh $(0.6 \mathrm{~m}, 1 / 8 \mathrm{inch}, 2.0 \mathrm{~mm})$ thermostated at $30^{\circ} \mathrm{C}$ and a thermal conductivity detector $\left(100^{\circ} \mathrm{C}\right)$. The $\mathrm{GC}$ analysis was arranged in a continuous flow mode, where a stable and precisely controlled stream of Ar carrier gas $\left(1.0 \mathrm{~mL} \mathrm{~min}^{-1}\right.$; mass-flow controller Bronkhorst EL Flow Select) flushed the gas-tight photo-electrochemical cell and then filled an injection loop $(100 \mathrm{~mL})$ in the chromatograph. The gas mixture in the injection loop was fed at specified intervals into the $\mathrm{GC}$ column where the concentration of $\mathrm{H}_{2}$ in the sample was measured. Calibration of the setup was performed using galvanostatic hydrogen evolution from a small area platinum working electrode and a $0.1 \mathrm{M} \mathrm{H}_{2} \mathrm{SO}_{4}$ aqueous electrolyte solution. Under these conditions, the faradaic efficiency was assumed to be $100 \%$. The temporal relationship between the photo-electrochemical and GC responses involves two delays which are discussed in detail in our previous work. ${ }^{24}$ 
Inductively Coupled Plasma Mass Spectroscopy. Quantification of transition metal concentrations in electrolyte solutions was carried out by ICP-MS analysis (NexION 350D or 2000B, Perkin-Elmer). Analysis solutions contained an aliquot of electrolyte solution acidified to give 1.4 vol. $\% \mathrm{HNO}_{3}$. $\mathrm{NiO}$ dissolutions involved the addition of $3 \mathrm{~mL}$ of an electrolyte solution to a dyed $\mathrm{NiO}$ film $\left(0.16 \mathrm{~cm}^{2}, 3.1 \mu \mathrm{m}\right)$ for 8 hours. Blank $\mathrm{NiO}$ film was dissolved in $2.5 \mathrm{~mL}$ aqua regia $\left(\mathrm{HNO}_{3 \text { (conc.) }}: \mathrm{HCl}_{\text {(conc.) }}, 1: 3\right.$ vol.) prior to subsequent dilutions. $\mathrm{Sc}, \mathrm{Ge}$ and $\mathrm{Rh}$ ions were plumbed into the sample inlet as internal standards to allow correction for matrix effects and instrumental drift. Raw analyte counts were standardized by means of calibration curves constructed through systematic dilutions of commercially available stock solutions. For electrolyte solutions pre/post measurement this was $1-100 \mathrm{ppb}$ and for $\mathrm{NiO}$ dissolution this was $0.1-1000 \mathrm{ppb}$. Linearity outside this range cannot be confirmed and all counts outside this should be considered estimates. Background (baseline) counts were based on 1.4 vol.\% $\mathrm{HNO}_{3}$ in Milli-Q water and were subtracted from all measurements. Five analyses of each sample were undertaken. Analysis of iron was conducted in Kinetic Energy Discrimination (KED) mode using a helium collision cell to eliminate the common polyatomic interference ${ }^{40} \mathrm{Ar}^{16} \mathrm{O}^{+} .66$

Transient Absorption Spectroscopy. Transient absorption spectroscopy (TAS) was performed using a Q-switched Nd-YAG laser (8 ns, 532 nm, 10 Hz, Quanta-Ray® INDI Spectraphysics) as a pump and a white quartz halogen lamp (Bentham IL1) as a probe. Probe intensity was adjusted through a combination of band, long pass and neutral density filters used in front of the sample. The transmitted probe beam was dispersed by a monochromator (CM110, SP) and detected by a silicon (HCAS-200M-Si, Femto) or an InGaAs photoreceiver (HCA-S-200M-IN, Femto). A digital oscilloscope (DPO 4054, Tektronix) was used to digitize the voltage signals using dc coupling and $50 \mathrm{U}$ impedance, typically averaging 512 pulses per measurement. The 
time resolution of the setup was around $40 \mathrm{~ns}$. Each photocathode was held at the designated potential for at least 3 mins prior to spectroscopic measurements.

\section{RESULTS}

Prior to investigating the photo-electrocatalytic properties of the PMI-6T-TPA-sensitized electrodes, the procedures for fabrication and the thickness of the mesoporous $\mathrm{NiO}$ layer were optimized by maximizing the photocurrent density for the reduction of cobalt(III) ethylenediamine in aqueous solutions, which is believed to be a fast outer-sphere electron transfer. $^{44}$ This optimization study demonstrated reasonable reproducibility of the photoelectroreductive properties of the examined DS electrodes (see experimental and Figure S1).

Transition metal contaminants in the electrolyte solutions. Further experiments were undertaken using solutions without intentionally-added redox active species to investigate the photo-electrocatalytic properties of the PMI-6T-TPA-sensitized NiO electrodes for the hydrogen evolution reaction. Notwithstanding conventional measures taken to preclude contamination, viz. extensive washing of the labware and the use of ultra-pure water $(18 \mathrm{M} \Omega \mathrm{cm})$, detectable concentrations of adventitious dissolved metals that could potentially serve as precursors for electrodeposited HER catalysts were detected in all solutions examined (Table 1). However, most contaminants were observed at levels close to the detection limit of 1 ppb with the exception of iron (detection limit $5 \mathrm{ppb}$ ), which was present at a comparatively large concentration of $c a 2.8 \mu \mathrm{M}$ in phosphate buffer and $0.3 \mu \mathrm{M}$ in citrate buffer. Most probably, these admixtures originated from the salts/acids, as the solvent was shown to be pure (Table 1).

Following photo-electrocatalytic experiments ( $\mathrm{ca}$ 4-12 h duration; vide infra), selected solutions were again analyzed by ICP-MS and a substantial increase in the concentration of nickel from undetectable to a $10^{1} \mu \mathrm{M}$ level was found. This change presumably results from the 
slow dissolution of the $\mathrm{NiO}$ support through defects not blocked by hydrophobic dye molecules. The NiO dissolution was additionally examined on DS electrodes kept in different solutions without applied potential under diffuse light for 8 hours, which resulted in the loss of 0.3 to $1.1 \%$ of the mesoporous support (Table S1). The differences in the amount of dissolved nickel were not substantial, though it is noted that sulfuric acid, acetate and formate buffers provided the most significant dissolution of $\mathrm{NiO}$ among tested electrolytes.

Table 1. Concentrations $(\mu \mathrm{M})$ of transition metals in studied electrolyte solutions as determined by ICP-MS.

\begin{tabular}{|c|c|c|c|c|c|c|c|c|c|}
\hline \multirow[b]{2}{*}{ Electrolyte } & \multirow[b]{2}{*}{$\mathrm{pH}$} & \multicolumn{2}{|c|}{$\mathrm{Fe}$} & \multicolumn{2}{|c|}{ Co } & \multicolumn{2}{|c|}{$\mathrm{Ni}$} & \multicolumn{2}{|c|}{ Mo } \\
\hline & & $\begin{array}{c}\text { As } \\
\text { prepared }\end{array}$ & $\operatorname{Post}^{[\mathrm{a}]}$ & $\begin{array}{c}\text { As } \\
\text { prepared }\end{array}$ & $\operatorname{Post}^{[a]}$ & $\begin{array}{c}\text { As } \\
\text { prepared }\end{array}$ & $\operatorname{Post}^{[a]}$ & $\begin{array}{c}\text { As } \\
\text { prepared }\end{array}$ & $\operatorname{Post}^{[a]}$ \\
\hline $\mathrm{H}_{2} \mathrm{O}(18 \mathrm{M} \Omega \mathrm{cm})$ & $\sim 7.0$ & $<0.090^{[\mathrm{b}]}$ & & $<0.017^{[\mathrm{c}]}$ & & $<0.017^{[\mathrm{c}]}$ & & $<0.021^{[\mathrm{c}]}$ & \\
\hline \multirow[t]{2}{*}{ 1.0 M Acetate } & 2.3 & 0.091 & & 0.037 & & 0.033 & & $<0.021$ & 0.023 \\
\hline & 4.0 & $<0.090$ & $<0.090$ & $<0.017$ & $<0.017$ & $<0.017$ & 57 & $<0.021$ & \\
\hline 1.0 M Citrate & 4.0 & 0.310 & & $<0.017$ & & $<0.017$ & & 0.077 & \\
\hline $1.0 \mathrm{M}$ Formate & 4.0 & 0.144 & & $<0.017$ & & $<0.017$ & & 0.028 & \\
\hline $0.2 \mathrm{M}$ Oxalate & 4.0 & 0.103 & $<0.090$ & $<0.017$ & $<0.017$ & $<0.017$ & 13 & $<0.021$ & $<0.021$ \\
\hline 1.0 M Phosphate & 7.0 & 2.8 & & $<0.017$ & & 0.030 & & 0.29 & \\
\hline \multirow[t]{2}{*}{ 1.0 M Propionate } & 2.1 & 0.12 & & $<0.017$ & & 0.067 & & 0.023 & \\
\hline & 4.0 & 0.12 & 0.17 & $<0.017$ & $<0.017$ & $<0.017$ & 36 & 0.034 & $<0.021$ \\
\hline $\begin{array}{l}\text { 1.0 M Pyridine/ } \\
\text { 1.0 M Acetate }\end{array}$ & 5.0 & $<0.090$ & & 0.034 & & 0.040 & & $<0.021$ & \\
\hline $0.1 \mathrm{M}$ Sulfate & $\sim 1.0$ & $<0.090$ & & $<0.017$ & & $<0.017$ & & $<0.021$ & \\
\hline
\end{tabular}

${ }^{a}$ After photo-electrochemical experiments. ${ }^{b}$ Limit of detection 5 ppb (Kinetic Energy Discrimination mode used to eliminate polyatomic interferences reduces the sensitivity). ${ }^{\mathrm{c}}$ Limit of detection $1 \mathrm{ppb}$.

Photo-electrocatalytic $\mathbf{H}_{2}$ evolution. Cyclic voltammograms of the unmodified PMI-6TTPA/NiO photocathodes do not demonstrate any noteworthy dependence on the chemical nature 
of the electrolyte or the solution $\mathrm{pH}$ (on the RHE potential scale), as exemplified in Figure 1a-c for acetate $(\mathrm{pH} 4)$ and citrate $(\mathrm{pH} 4)$ buffers as well as for the sulfuric acid solution ( $\mathrm{pH} 1)$. In all cases, the voltammetric curves exhibited a faradaic process attributed to a surface-confined $\mathrm{Ni}^{2+/ 3+}$ transition. ${ }^{45,46}$ This was observed with a mid-point potential of $c a$ 0.9-1.0 V vs. RHE, while there were no noticeable peaks at more reductive potentials. The magnitude of the reductive photocurrent density generated under 1 sun illumination at potentials less positive than $0.50 \mathrm{~V} v s$. RHE was also weakly influenced by the electrolyte and $\mathrm{pH}$, and was typically within the $10-40 \mu \mathrm{A} \mathrm{cm}^{-2}$ range, concordant with our previous report. ${ }^{24}$

Given the detectable level of transition metal contamination in the examined solutions (Table 1), the observed reductive photocurrent cannot be solely attributed to the catalytic evolution of $\mathrm{H}_{2}$. The latter must be quantitatively analyzed by an independent method like gas chromatography to establish the faradaic efficiency of the photo-electroreduction process. Dihydrogen detection was undertaken herein during long-term potentiostatic experiments in a 'flow-through' setup, as detailed in the experimental section. Photocathodes were tested at $0.00 \mathrm{~V} v s . \mathrm{NHE}(0.059 \mathrm{pH} \mathrm{V} v s . \mathrm{RHE})$ as a $\mathrm{pH}-$-independent reference, and at $0.05 \mathrm{~V} v s$. RHE in a consecutive measurement. At either potential, electrocatalytic $\mathrm{H}_{2}$ evolution cannot occur and additional driving force provided by the dye under irradiation is needed. Under the potentiostatic conditions employed, the reductive photocurrent density rapidly decreased in all cases until reaching quasi-steady-state values within the microampere per $\mathrm{cm}^{2}$ range (all current densities are normalized to the geometric surface area hereinafter). The current-time transients and parallel $\mathrm{H}_{2}$ gas detection are exemplified in Figure 2 and Figure S2 with the reduction photocurrent density $\left(j_{\mathrm{hv}} / \mu \mathrm{A} \mathrm{cm}{ }^{-2}\right)$ and faradaic efficiency $(\varepsilon / \%)$ data summarized in Table 2 and Table S2. 
Tabulated photocurrent density values were calculated by using the dark current density at the end of the measurement at each potential as a baseline. ${ }^{47}$
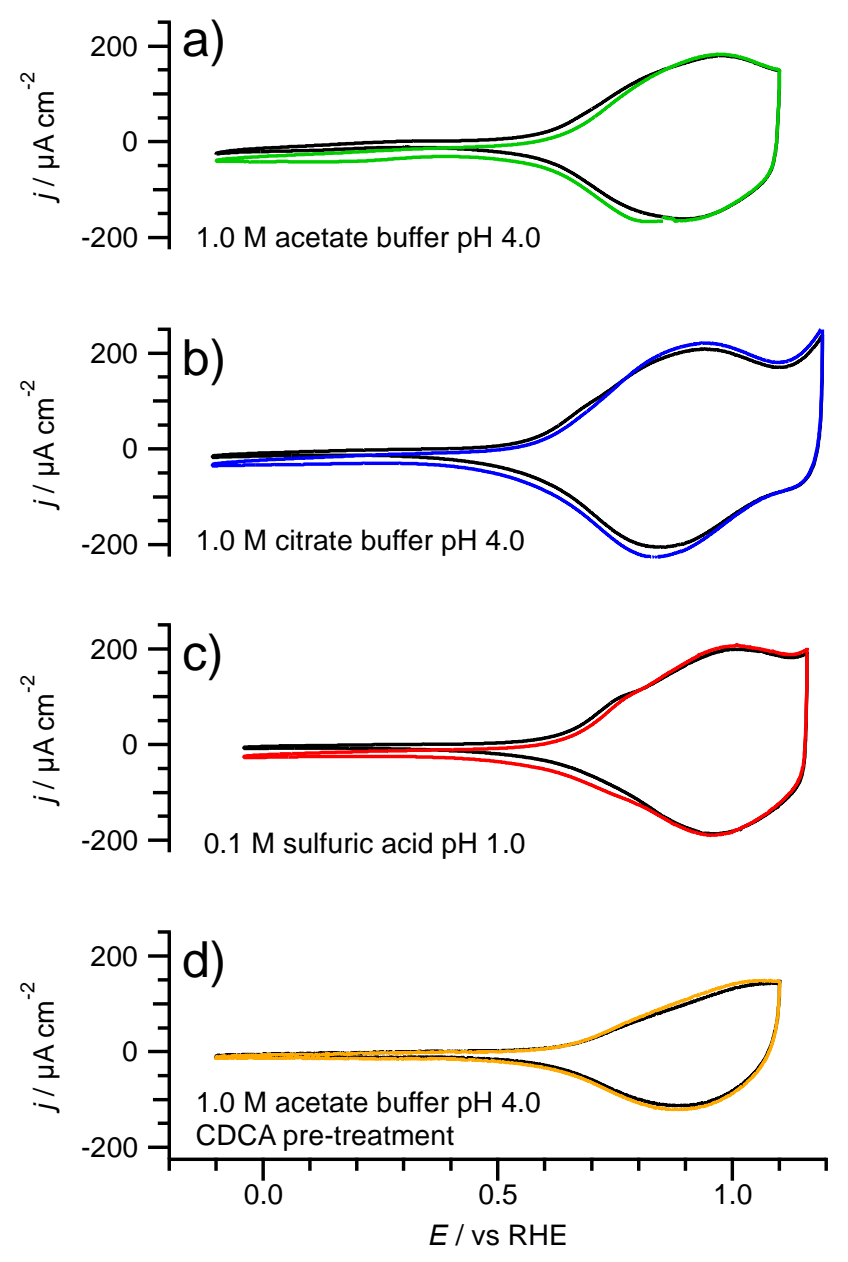

Figure 1. Cyclic voltammograms (scan rate, $v=0.020 \mathrm{~V} \mathrm{~s}^{-1}$ ) of the PMI-6T-TPA-sensitized NiO photocathodes in contact with Ar-saturated aqueous (a) acetate buffer (1.0 M, pH 4.0), (b) citrate buffer (1.0 M, pH 4.0) and (c) sulfuric acid (0.1 M, pH 1.0) in the dark (black) and under visible light illumination (100 mW cm${ }^{-2}$, AM 1.5G, $\left.\lambda>400 \mathrm{~nm}\right)$ (green, blue, red). Panel (d) shows the data for measurements undertaken with a photocathode pre-treated with chenodeoxycholic acid (CDCA) in contact with Ar-saturated acetate buffer (1.0 M, pH 4.0) under irradiation (orange) and in the dark (black). Quasi-stabilized, typically third, scans are shown. 


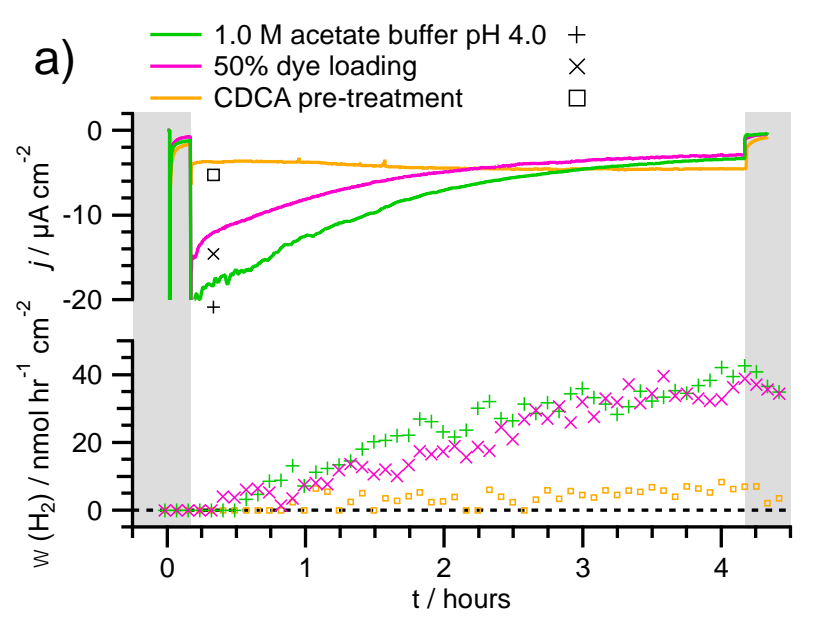

b) $\quad 1.0 \mathrm{M}$ Citrate buffer $\mathrm{pH} 4.0+$

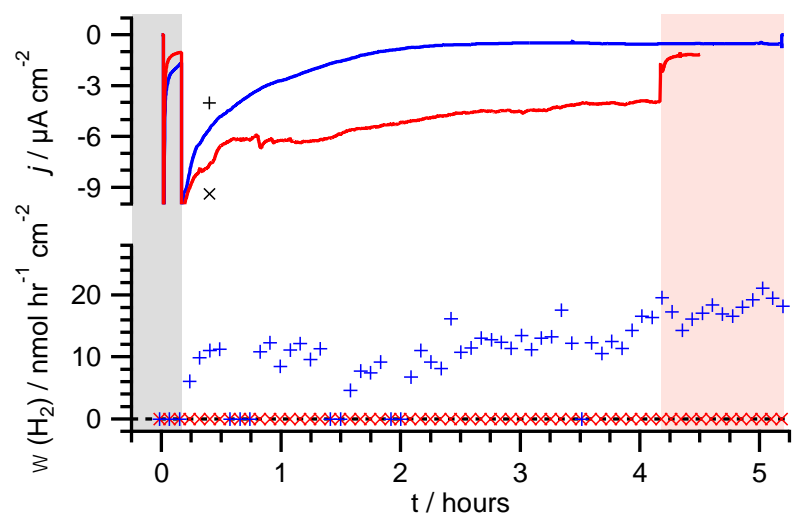

Figure 2. Chronoamperograms (top sections) and the rate of $\mathrm{H}_{2}$ generation $\left(\omega_{\mathrm{H} 2}\right)$ (bottom sections) measured during photo-electroreduction of Ar-saturated (a) acetate buffer (1.0 M, pH 4.0), (b) citrate buffer (1.0 M, pH 4.0) and sulfuric acid (0.1 M, pH 1.0) solutions with PMI-6TTPA-sensitized $\mathrm{NiO}$ electrodes under 1 sun irradiation at $0.00 \mathrm{~V}$ vs. NHE. In panel a, data are shown for the photocathodes as prepared (green), or that were additionally modified with CDCA (orange), or treated with $0.01 \mathrm{M} \mathrm{NaOH}$ in an ethanol : dichloromethane solution (1:1 vol.) to remove $c a 50 \%$ of adsorbed dye (magenta). The shaded areas indicate time periods of no illumination, with the red shading in panel $\mathbf{b}$ specific to the measurement in $0.1 \mathrm{M} \mathrm{H}_{2} \mathrm{SO}_{4}$. 
Table 2. Photo-electrocatalytic $\mathrm{H}_{2}$ generation by PMI-6T-TPA-sensitized NiO cathodes (jhv - photocurrent density; $\omega_{\mathrm{H} 2}-$ rate of $\mathrm{H}_{2}$ generation; $\varepsilon$ - faradaic efficiency).

\begin{tabular}{|c|c|c|c|c|c|c|c|}
\hline \multirow[b]{2}{*}{ Electrolyte } & \multirow[b]{2}{*}{$\mathrm{pH}$} & \multicolumn{3}{|c|}{$0 \mathrm{~V} v s . \mathrm{NHE}(0.059 \mathrm{pH} \mathrm{V} v s . \mathrm{RHE})$} & \multicolumn{3}{|c|}{$0.050 \mathrm{~V} v$ s. RHE } \\
\hline & & $\begin{array}{c}j_{\mathrm{hv}} / \\
\mu \mathrm{A} \mathrm{cm}^{-2} \text { a }\end{array}$ & $\begin{array}{c}\omega_{\mathrm{H} 2} / \\
\mathrm{nmol} \mathrm{h}^{-1} \mathrm{~cm}^{-2} \mathrm{a}\end{array}$ & $\varepsilon / \%$ & $\begin{array}{c}j_{\mathrm{hv}} / \\
\mu \mathrm{A} \mathrm{cm}^{-2} \text { a }\end{array}$ & $\begin{array}{c}\omega_{\mathrm{H} 2} / \\
\mathrm{nmol} \mathrm{h}^{-1} \mathrm{~cm}^{-2} \text { a }\end{array}$ & $\varepsilon / \%$ \\
\hline 1.0 M Acetate ${ }^{\mathrm{b}}$ & 4.0 & $4.4 \pm 0.8$ & $35 \pm 4$ & $49 \pm 9$ & - & - & - \\
\hline \multirow[t]{2}{*}{ 1.0 M Acetate ${ }^{\mathrm{c}}$} & 4.0 & 4.2 & 35 & 45 & 3.2 & 42 & 71 \\
\hline & 2.3 & 6.2 & 40 & 35 & 5.0 & 40 & 43 \\
\hline 1.0 M Acetate ${ }^{\mathrm{d}}$ & 4.0 & 3.8 & 14 & 20 & 2.7 & 16 & 32 \\
\hline 1.0 M Acetate ${ }^{\mathrm{e}}$ & 4.0 & 2.4 & 35 & 78 & - & - & - \\
\hline 1.0 M Oxalate & 4.0 & 2.2 & 17 & 42 & - & - & - \\
\hline 1.0 M Citrate & 4.0 & 0.6 & 15 & 134 & 0.8 & 15 & 101 \\
\hline \multirow[t]{2}{*}{ 1.0 M Propionate } & 4.0 & 2.8 & $<7$ & $<13$ & 2.9 & $<7$ & $<13$ \\
\hline & 2.1 & 1.9 & $<7$ & $<20$ & 1.4 & $<7$ & $<27$ \\
\hline 1.0 M Sulfate & 1.0 & 2.7 & $<7$ & $<14$ & 2.2 & $<7$ & $<17$ \\
\hline
\end{tabular}

\footnotetext{
${ }^{a}$ Values taken from a point just prior to the end of the illumination. ${ }^{\mathrm{b}}$ Averaged across four electrodes with a geometric area of 1 (two samples) and $2 \mathrm{~cm}^{2}$ (two samples). ${ }^{\mathrm{c}}$ Individual measurement with 2 consecutively applied potentials (Figure S2g). ${ }^{\mathrm{d}}$ Photocathode was pre-treated with $\mathrm{CDCA} .{ }^{\mathrm{e}}$ Photocathode was pre-treated with $0.01 \mathrm{M} \mathrm{NaOH}$ in an ethanol : dichloromethane solution (1:1 vol.) to desorb ca $50 \%$ of the dye.
}

When the absolute value of the photocurrent was below 1 microampere, a high level of uncertainty was present in the results, especially in the determination of the faradaic efficiency. In particular, this applied to the photo-electrocatalytic tests undertaken with the citrate buffer where $j_{\mathrm{hv}}$ and the amount of evolved $\mathrm{H}_{2}$ were very low, rendering the quantification of both subject to a significant experimental error (Table 2). Nevertheless, these results can be confidently interpreted as a qualitative confirmation of the photo-electrocatalytic effect 
(Figure S2), which is very weak and consequently cannot be quantified reliably. In other cases where $j_{\mathrm{hv}}$ was above $2 \mu \mathrm{A} \mathrm{cm}{ }^{-2}$ and reasonable amount of $\mathrm{H}_{2}$ was evolved, the faradaic efficiency also demonstrated some variability, though within a satisfactory, physically sensible range (e.g. see data for the acetate electrolyte in Table 2 and Table S2). We estimate our detection limit for $\mathrm{H}_{2}$ generated via the photo-electrocatalytic reaction at $\omega_{\mathrm{H} 2}>7 \mathrm{nmol}$ hour ${ }^{-1} \mathrm{~cm}^{-2}$ with $1 \mathrm{~cm}^{2}$ electrodes (chromatograms exemplified in Figure S3).

In our previous work, ${ }^{24} \mathrm{H}_{2}$ generation was observed when the photocathodes were tested in the presence of phosphate buffer $(1.0 \mathrm{M}, \mathrm{pH} 7.0)$, although any $\mathrm{H}_{2}$ generation was below the detection limit in $\mathrm{H}_{2} \mathrm{SO}_{4}(0.1 \mathrm{M}, \mathrm{pH}$ 1.0). To observe the influence of the nature of the electrolyte anion, further electrolyte compositions were investigated. The use of organic electrolytes such as acetate, citrate and oxalate enabled photo-electrocatalytic $\mathrm{H}_{2}$ evolution by the DS cathode, with the consistently highest rates achieved in the presence of the $\mathrm{CH}_{3} \mathrm{COO}^{-}$ anion (Figure 2, Figure S2 and Table 2). Conversely, no $\mathrm{H}_{2}$ evolution was detected with phosphate (1.0 M, $\mathrm{pH} 7.0)$, propionate (1.0 M, $\mathrm{pH} 4.0)$, formate (1.0 M, $\mathrm{pH} 4.0)$, sulfate (1.0 M, $\mathrm{pH}$ 4.0) or pyridine/acetate (1.0 M, pH 5.0); nor with $0.1 \mathrm{M} \mathrm{H}_{2} \mathrm{SO}_{4} / \mathrm{Na}_{2} \mathrm{SO}_{4}$ in $\mathrm{H}_{2} \mathrm{O}$ and $\mathrm{CH}_{3} \mathrm{CN}$ (1 : 1 vol.), or phosphate $\left(0.1 \mathrm{M}, \mathrm{pH} 7.0\right.$ with added $0.9 \mathrm{M} \mathrm{LiBF}_{4}$ and $0.1 \mathrm{M}$ n-methyl benzimidazole). It is important to emphasize that this does not necessarily mean that the photoelectrocatalytic reaction is impossible with the given electrolyte systems, rather that the dihydrogen generation rates $\left(\omega_{\mathrm{H} 2}\right)$ were below $7 \mathrm{nmol} \mathrm{hour}{ }^{-1} \mathrm{~cm}^{-2}$ under our conditions. The combination of this detection limit with a smaller electrode size in the present study $\left(1 \mathrm{~cm}^{2}\right)$, means that $\mathrm{H}_{2}$ evolution in $1.0 \mathrm{M}$ phosphate is undetectable herein, whereas we previously measured rates of $c a .5 \mathrm{nmol}$ hour ${ }^{-1} \mathrm{~cm}^{-2}$ with geometrically larger electrodes $\left(2 \mathrm{~cm}^{2}\right.$ used in Ref. $\left.^{24}\right)$. 
Typically, the $j_{\mathrm{hv}}$ values recorded at $0 \mathrm{~V} v s$. NHE $(0.059 \mathrm{pH} \mathrm{V} v s$. RHE) and $0.05 \mathrm{~V} v s$. RHE were very similar (Figure S2), which reflects weak dependence of the photocurrent on applied potential within the range examined and is consistent with the voltammetric data (Figure 1). However, in some cases, values of $j_{\mathrm{hv}}$ obtained at $0.059 \mathrm{pH} \mathrm{V} v s$. RHE were unexpectedly slightly higher than those derived from subsequent measurements at the more negative potential of $0.05 \mathrm{~V}$ vs. RHE (Table 1), presumably reflecting slow degradation of the electrodes. It is important to note that the detected hydrogen evolution never occurred at $100 \%$ faradaic efficiency, meaning that other photo-electrochemical process(es) always contributed to the measured $j_{\mathrm{hv}}$.

In contrast to the pronounced effect of the electrolyte anion on the photo-electrochemical generation of $\mathrm{H}_{2}$ by PMI-6T-TPA-sensitized cathodes, no obvious of influence of $\mathrm{pH}$ on $\omega_{\mathrm{H} 2}$ was established. Indeed, notwithstanding some differences in the photo-electroreduction current density between sodium acetate buffer $(\mathrm{pH} 4.0)$ and acetic acid $(\mathrm{pH} 2.2)$, or between $\mathrm{Na}_{2} \mathrm{SO}_{4}\left(\mathrm{pH}\right.$ 4.0) and $\mathrm{H}_{2} \mathrm{SO}_{4}(\mathrm{pH}$ 1.0), the rates of the hydrogen gas generation were not significantly affected by changing the concentration of hydroxonium (Figure 2, Figure S2, Table 2 and Table S2). The illumination intensity within the range 0.2 to 2 suns was also found to weakly influence $\mathrm{H}_{2}$ evolution (Figure S4).

Several experiments were undertaken using acetate-buffered solutions with intentionallyintroduced dissolved nickel as a potential precursor for an electrodeposited HER catalyst. In one type of measurement, a PMI-6T-TPA-sensitized cathode was studied in the presence of $1 \mathrm{mM}$ $\mathrm{Ni}\left(\mathrm{CH}_{3} \mathrm{COO}\right)_{2}$. Introduction of this substantial amount of dissolved $\mathrm{Ni}^{2+}$ did not significantly affect the photocurrent density at the start of the experiment. However, it provided a more stable $j_{\text {hv }}$ in the longer term that resulted in a value of $8.2 \mu \mathrm{A} \mathrm{cm}{ }^{-2}$ after 4 hours of measurement 
(Figure S5, Table S2), which is approximately double that for an initially Ni-free solution. At the same time, the addition of notable amounts of dissolved $\mathrm{Ni}^{2+}$ significantly delayed the onset of $\mathrm{H}_{2}$ generation and suppressed the quasi-steady-state rate (25 vs. $30-40 \mathrm{nmol}_{\mathrm{H} 2} \mathrm{hr}^{-1} \mathrm{~cm}^{-2}$ ), eventuating in decreased faradaic efficiency of the process (Table S2). In another type of experiment, electrodes were prepared with an extra $1 \mathrm{~cm}^{2}$ of unmodified $\mathrm{NiO}$ film adjacent to the dyed layer (photograph in Figure S6). The unmodified nickel oxide part of the cathode was not illuminated during experiments and served as a source of slowly dissolving nickel species to the solution. Under these conditions, a comparatively large initial reductive photocurrent density of unknown origin was observed ( $c a-55 \mu \mathrm{A} \mathrm{cm}{ }^{-2}$ ), which decreased quickly and trended towards the $j_{\mathrm{hv}}$ value found with a conventional photocathode configuration after several hours of measurements ( $c a .-5 \mu \mathrm{A} \mathrm{cm}^{-2}$; Figure S5). No influence of the additional source of nickel leaching into the solution on the $\mathrm{H}_{2}$ generation rate during the initial 2 hours of the experiments was found, but suppression of $\omega_{\mathrm{H} 2}$ was observed for the subsequent 2 hours.

Finally, the effects of two types of pre-treatment on the photo-electrocatalytic properties of the PMI-6T-TPA-sensitized NiO electrodes were explored. In one case, the photocathodes were modified with chenodeoxycholic acid (CDCA) to block surface sites on the mesoporous $\mathrm{NiO}$ support where the dye failed to adsorb. This resulted in a noticeable suppression of the $\mathrm{Ni}^{2+} / \mathrm{Ni}^{3+}$ voltammetric peaks when compared to untreated DS cathodes in the same media, indicating improved surface passivation ( $c f$. Figure 1a and Figure 1d). Most importantly, despite similar amplitudes of the quasi-stable current density observed during long-term photo-electrochemical experiments, a significant suppression in $\mathrm{H}_{2}$ generation rate was detected (ca 7 vs. $40 \mathrm{nmol} \mathrm{h}^{-1}$ $\mathrm{cm}^{-2}$ ). An alternative pre-treatment involved soaking the sensitized electrodes in $0.01 \mathrm{M} \mathrm{NaOH}$ in an ethanol : dichloromethane solution (1: 1 vol.). This desorbs $c a 50 \%$ of the dye as 
determined by UV-Vis spectrophotometry. Such pre-treatment induced a slight improvement in the $\mathrm{H}_{2}$ evolution rate at the initial stages, despite the halving of the concentration of photo-active species on the electrode surface (Figure 2). In the quasi-steady-state regime, there was no loss in $\omega_{\mathrm{H} 2}$ and the faradaic efficiency was significantly improved upon partial bleaching of the photocathode (Table 2).

Transient absorption spectroscopy. In principle, a specific electrolyte environment can alter the position of the $\mathrm{NiO}$ valence band edge, ${ }^{48,49}$ and consequently the thermodynamic driving force for charge injection from the photo-excited dye. This effect might change the rate of charge recombination (equation 6c), and thereby the photo-electrocatalytic performance of the DS electrode. A higher rate of recombination leads to a shorter lifetime of the photo-reduced dye, which can be probed by transient absorption spectroscopy (TAS). ${ }^{18,28,50,51}$

All TAS measurements were undertaken herein with a probe wavelength of $800 \mathrm{~nm}$ where the dye anion absorbs ${ }^{28}$ (Figure S7) and at the same potential as that used in the photoelectrocatalytic experiments $\left(0 \mathrm{~V} v s\right.$. NHE), where the band gap states are full. ${ }^{52}$ The dye-anion signal was also the most long lived at this potential (Figure S8). Under our conditions, transient absorption measurements on the same photocathode in $1.0 \mathrm{M}$ sodium acetate buffer did not reveal well-defined changes in the dynamics of spectral decay upon changing $\mathrm{pH}$ within the 4.19.1 range (Figure S9). Similar invariance was observed in sodium phosphate buffer across a wider $\mathrm{pH}$ range from 2 to 12 in the temporal region faster than $10 \mu$ s (Figure S9). However, there appears to be a slight dependence of the spectral decay on the solution $\mathrm{pH}$ at longer timescales.

TAS data were obtained in the presence of $1.0 \mathrm{M}$ phosphate, acetate and sulfate electrolytes at pH 4.1 (Figure 3), though no obvious correlation with the photo-electrocatalytic performance was identified. The half-life of the photo-generated dye-anion $\left(t_{1 / 2}\right)$ recorded with the $\mathrm{CH}_{3} \mathrm{COO}^{-}$ 
and $\mathrm{SO}_{4}{ }^{2-}$ anions is essentially the same $(\sim 20 \mu \mathrm{s})$, while there is a 5 -fold difference in the rates of $\mathrm{H}_{2}$ evolution (Table 2). Somewhat faster decay is observed when phosphate is used as the electrolyte $\left(t_{1 / 2} \approx 10 \mu \mathrm{s}\right)$. Photo-electrocatalytic hydrogen generation is very slow under these conditions, although this is also the case in the presence of the sulfate anion. As such, this increased decay could instead be due to the dye reducing iron from the quantified contamination in the electrolyte (Table 1).

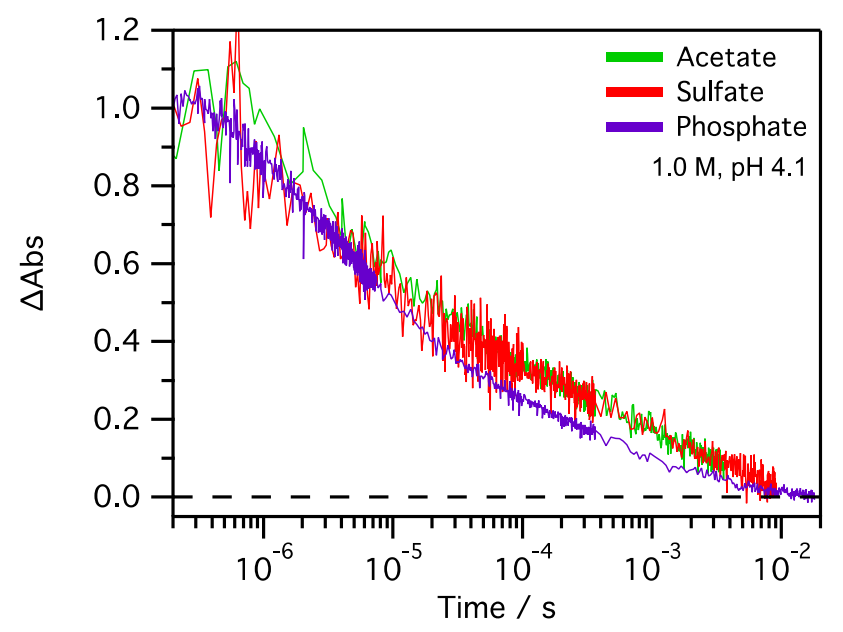

Figure 3. Normalized transient absorption decay recorded for the PMI-6T-TPA-sensitized NiO films in contact with Ar-saturated 1.0 M sodium acetate buffer (green), 1.0 M sodium phosphate buffer (purple) and $1.0 \mathrm{M} \mathrm{Na}_{2} \mathrm{SO}_{4}$ (red) at $\mathrm{pH} 4.1$. Observation wavelength: $850 \mathrm{~nm}$; excitation wavelength: $532 \mathrm{~nm}$; pulse energy: $100 \mu \mathrm{J} \mathrm{cm}^{-1}$.

\section{DISCUSSION}

Hydrogen generation was unambiguously observed on the PMI-6T-TPA-sensitized NiO electrodes maintained at potentials more positive than $0 \mathrm{~V} v s$. RHE and under 1 sun illumination in aqueous electrolyte solutions, in confirmation of previous results. ${ }^{24}$ The rate of this generation was found to depend very weakly (if at all) on illumination intensity, $\mathrm{pH}$ and dye loading amongst other variables tested. However, if the reaction would occur on the dye surface via a 
classical way as depicted in mechanism I (Scheme 1), then one would expect the rate of the reaction to be strongly dependent on all of these parameters. Firstly, variation in illumination intensity affects the number of photo-generated electrons on the dyes, which would subsequently alter the rate of the Volmer reaction step. Secondly, increases in the substrate concentration by at least an order of magnitude should increase the rates of all of the elementary steps. Finally, a reduced concentration of dye on the surface would also lower the concentration of active sites and therefore result in slower kinetics. On this basis, we adjudge that the contribution of mechanism I to the photo-electrocatalytic generation of molecular hydrogen by the PMI-6TTPA-sensitized $\mathrm{NiO}$ cathode is minimal, and that electrocatalytic sites, which are not provided by the dyed surface, are required to sustain adsorption and successive reduction of $\mathrm{H}^{+}$.

As suggested in mechanism II (Scheme 1), transition metal particles (photo-)electrodeposited on the cathode surface from admixtures present in solutions might function as the required electrocatalytic sites. Such deposits are frequently observed in the field of electrocatalytic water splitting, ${ }^{32-39}$ and charge-transfer between heterogeneous catalysts and dye molecules has also been previously reported. ${ }^{24,25,53,54}$ Common transition metals capable of catalyzing $\mathrm{H}_{2}$ evolution include cobalt, nickel, iron and molybdenum. ${ }^{40,55,56}$ However, ICP-MS analysis of the electrolyte solutions used herein did not show significant presence of admixtures except for iron in the phosphate and citrate buffers. Importantly, no clear correlation exists between the concentrations of iron in the solutions (Table 2) and the corresponding photo-electrocatalytic performance of the photocathodes (Table 1). On the other hand, further ICP-MS analysis clearly demonstrates the presence of significant amounts of dissolved nickel $\left(>10^{1} \mu \mathrm{M}\right)$, which is unsurprising given the instability of the underlying $\mathrm{NiO}$ semiconductor at $\mathrm{pH}<10$ (Figure S10). ${ }^{57,58}$ At the same time, the reduction potential of the dye anion is $-0.70 \mathrm{~V} v s . \mathrm{NHE},{ }^{27,28}$ while the phase transition of the 
two-electron reduction of $\mathrm{Ni}^{2+}$ to $\mathrm{Ni}^{0}$ occurs at $c a-0.4 \mathrm{~V}$ vs NHE. ${ }^{58}$ Thus, a thermodynamic driving force of $c a 0.3 \mathrm{~V}$ exists for nickel deposition, and $\mathrm{Ni}^{0}$ is then expected to remain metastable (Fig S10). This surface could then provide electrocatalytic sites for the observed generation of $\mathrm{H}_{2}$, similar to electrodeposited platinum metal in our previous work. ${ }^{24}$ Such dissolution, deposition and HER catalysis has been previously proposed with nickel electrodes in acidic solutions, ${ }^{43}$ and nickel in general has long been known to be a reasonably efficient catalyst for the hydrogen evolution reaction. ${ }^{40-43}$

Ideally, electron microscopy techniques would be used to gather direct evidence of deposited particles, as in previous reports. ${ }^{32-35}$ However the large nickel background from the mesoporous $\mathrm{NiO}$ electrode inhibits such direct observations. Instead, low faradaic efficiencies found for experiments undertaken with enhanced concentrations of $\mathrm{Ni}^{2+}$ clearly suggest it is indeed electroreduced by the PMI-6T-TPA-sensitized photocathodes (since $\mathrm{Ni}^{+}$is unknown, the product is logically $\mathrm{Ni}^{0}$ ). At the same time, excessively large concentrations of dissolved nickel do not improve the $\mathrm{H}_{2}$ evolution rate. Thus, if mechanism II applies, then the concentration of $\mathrm{Ni}^{2+}$ precursor should be maintained at some optimal level to sustain the metastable state of the electrodeposited catalyst without suppressing the hydrogen evolution reaction through further deposition and parasitic occupation of the photo-electrochemically active sites.

One could hypothesize that different anions could alter dissolution rates to achieve this operational level. This might help explain the unexpected effect of the electrolyte anion on the photo-catalytic capacity of the DS cathodes. The order of the electrolyte anion dependence for photo-electrochemical $\mathrm{H}_{2}$ evolution by the PMI-6T-TPA-sensitized photocathodes was found to be acetate $>$ citrate, oxalate $>>$ propionate, formate, phosphate, sulfate. However, there is no correlation between the amount of dissolved $\mathrm{Ni}^{2+}$ and the observed photo-electrocatalytic effect. 
Indeed, similar levels are found in sulfuric acid, formate and acetate, but $\mathrm{H}_{2}$ generation is observed in the latter case only. Thus, the combined data on the dissolution of nickel oxide and the presence of other metal admixtures in solutions reported herein do not provide an explanation of the electrolyte-dependent photo-electrocatalytic performance of the PMI-6T-TPA-sensitized cathodes. Further work is needed to understand the origin of the observed electrolyte dependence. TAS analysis shows similar rates of charge recombination in different electrolyte solutions (Figure 3), ruling out electronic impacts of the anion on the $\mathrm{NiO}$ valence band. Furthermore, $t_{1 / 2}$ values are significantly longer (at $\left.10^{1} \mu \mathrm{s}\right)$ than those expected for electron transfer between dye molecules and hydrogen evolution catalysts, which have been show to occur on the scale of nanoseconds or even faster. ${ }^{10,18,30}$ At this stage, the role of anion is not understood and experimental techniques available to us cannot provide further insights beyond those reported above.

Although the significance of mechanism II cannot be discarded, there is also no clear-cut confirmation that it is the dominant pathway for $\mathrm{H}_{2}$ generation. Apart from the significant electrolyte anion effect on $\omega_{\mathrm{H} 2}$, the rate of the reaction herein was most influenced by the pretreatment of the electrode by CDCA. Through adsorption onto accessible $\mathrm{MO}_{x}(\mathrm{M}=\mathrm{Ti}, \mathrm{Ni})$ sites, CDCA molecules have been previously used in DSSCs to improve device performance ${ }^{59-63}$ via suppression of interfacial charge-recombination reactions ${ }^{64}$ - a major energy loss pathway in this type of device. Without labile redox species, this pathway is less significant in DSPECs, although CDCA has been found to stabilize photocurrent in a reported $\mathrm{H}_{2}$-evolving DS photocathode..$^{20}$

Herein, adsorption of CDCA onto the PMI-6T-TPA-sensitized photocathodes substantially decreased their $\mathrm{H}_{2}$-evolving capability (Figure 2a). Meanwhile, lowering the dye loading on the 
electrode by $50 \%$, i.e. exposing more $\mathrm{NiO}$ sites to the electrolyte solution, does not suppress $\mathrm{H}_{2}$ generation. On the contrary, the rate of the hydrogen evolution reaction normalized to the amount of dye is enhanced by a factor of two compared to a fully covered photo-cathode (Figure 2a). The improvement in performance is also clearly reflected by significantly enhanced faradaic efficiency (Table 2). Changes in the $\mathrm{Ni}^{2+}$ concentration and availability of the $\mathrm{NiO}$ leaching sources does not clearly affect the $\mathrm{H}_{2}$ generation rate (Figure S5 and Table S2), and therefore cannot be invoked to explain the effects of CDCA adsorption and partial bleaching of the dyesensitized electrodes. On the other hand, the aforementioned treatments obviously change the surface density of the interfaces between dye molecules and any disconnected, unmodified $\mathrm{NiO}$ that are in contact with the electrolyte solution, leading to the conclusion that the photoelectrocatalytic $\mathrm{H}_{2}$ generation by the PMI-6T-TPA-sensitized photocathodes primarily occurs via the mechanism most dependent on these interfaces, viz. mechanism III (Scheme 1). Indeed, decreasing the concentration of these interface sites through adsorption of CDCA results in lower photo-electrocatalytic reaction rate. Meanwhile, decreased dye loading, resulting in more interfaces, leads to greater $\mathrm{H}_{2}$ evolution (per dye molecule) and a higher faradaic efficiency. The precise origin of the electrocatalyst at these dye $\mid \mathrm{NiO}$ sites is unknown, but our present results indicate either the reduction of poorly fused sections of the $\mathrm{NiO}$ surface and/or dissolved $\mathrm{Ni}^{2+}$ to metallic nickel, which is meta-stable (Fig S10) and can catalyze the hydrogen evolution reaction under the examined conditions.

On the basis of the above, we conclude that $\mathrm{H}_{2}$ generation predominately occurs via mechanism III (Scheme 1). Photo-generated charges allow the formation of a $\mathrm{Ni}^{0}$ catalyst, presumably from dissolved $\mathrm{Ni}^{2+}$, at the interfaces between adsorbed dye molecules and disconnected $\mathrm{NiO}$ particles that act as nucleation sites. Nickel-metal catalyst formed at these 
interfaces is capable of accepting the photo-generated electrons from the dye and provides active sites for hydrogen adsorption and subsequent $\mathrm{H}-\mathrm{H}$ bond formation.

\section{CONCLUSIONS}

In summary, we have investigated $\mathrm{H}_{2}$ generation on DS photocathodes without intentionallyadded HER catalysts and considered three feasible mechanisms to rationalize this phenomenon. Our data do not support the hypothesis that the dye alone is responsible for the observed $\mathrm{H}_{2}$ generation. Nor can the presence of transition metal ions in solutions, either as contamination or due to dissolution of the $\mathrm{NiO}$ semiconductor, that can be (photo-)electroreduced to form a hydrogen evolution catalyst on the photo-cathode surface be considered as the limiting factor determining the $\mathrm{H}_{2}$-evolving capability of the dye-sensitized electrodes either. Instead, the key role of the interfaces between the adsorbed dye molecules and poorly-connected or disconnected $\mathrm{NiO}$ particles in the mesoporous support was identified. These interfaces are suggested to serve as photo-active sites for the formation of a $\mathrm{Ni}^{0}$ electrocatalyst, which can accept photo-generated electrons from the contiguous dye molecules and thereby sustain the hydrogen reduction reaction. The source of this catalyst is most probably dissolved $\mathrm{Ni}^{2+}$ that was found to be released to the solution from $\mathrm{NiO}$ in appreciable concentrations of $10^{1} \mu \mathrm{M}$ during photoelectrochemical experiments.

The rate of light-driven dihydrogen generation via the postulated mechanism shows an unexpected dependence on the chemical nature of the electrolyte anion present. Transient absorption spectroscopic studies indicate that the electrolyte effect is not caused by changes in the charge-recombination kinetics, and that the lifetime of the photo-reduced dye is sufficient to allow for electron transfer. The effects of contaminants and various levels of $\mathrm{NiO}$ dissolution provided by different electrolytes were also ruled out. Although the origin of this electrolyte 
effect requires further investigation, we believe that this phenomenon may have important implications for the design of efficient DS photo-electrode systems which function in aqueous solutions for both solar fuel synthesis and solar cell technologies.

The best photo-electrochemical production of dihydrogen by a dye-sensitized photo-cathode without an intentionally-introduced catalyst was observed herein with the presence of acetate anions at the rate of $35-40 \mathrm{nmol} \mathrm{h}^{-1} \mathrm{~cm}^{-2}$. This is only 14-fold lower than the rate achieved with the most efficient DS photocathodes for water-splitting reported to date $\left(\mathrm{see}^{24}\right.$ and references therein). It is therefore important to consider the effects of dissolved transition metal ions, dye $\mid \mathrm{NiO}$ interfaces, and chemical nature of the electrolyte in future work focused on development and mechanistic interpretation of dye-sensitized cathodes for hydrogen generation even in the presence of an intentionally-introduced catalyst.

\section{ASSOCIATED CONTENT}

Supporting Information. The Supporting Information is available free of charge on the ACS publications website: photo-electrochemical data and $\mathrm{H}_{2}$ generation rates; nickel dissolution data; gas chromatograms; photocathode photograph; transient absorption spectra and decays; Pourbaix diagram for nickel.

\section{Corresponding Author}

* E-mail: alexandr.simonov@monash.edu

\section{Notes}

The authors declare no competing financial interest.

\section{ACKNOWLEDGMENTS}


The authors acknowledge the ARC Centre of Excellence for Electromaterials Science for financial support and Dr. Kate Nairn (Monash University) for proofreading of this paper.

\section{Funding Sources}

Australian Research Council through the ARC Centre of Excellence for Electromaterials Science (Grant No. CE140100012).

\section{REFERENCES}

(1) Ciamician, G. The Photochemistry of the Future. Science 1912, 36, 385-394.

(2) Lewis, N. S.; Nocera, D. G. Powering the Planet: Chemical Challenges in Solar Energy Utilization. Proc. Natl. Acad. Sci. 2006, 103, 15729-15735.

(3) Styring, S. Artificial Photosynthesis for Solar Fuels. J. Chem. Soc. Faraday Trans. 2012, $155,357-376$.

(4) Cook, T. R.; Dogutan, D. K.; Reece, S. Y.; Surendranath, Y.; Teets, T. S.; Nocera, D. G. Solar Energy Supply and Storage for the Legacy and Non Legacy Worlds. Chem. Rev. 2010, $110,6474-6502$.

(5) Song, W.; Chen, Z.; Glasson, C. R. K.; Hanson, K.; Luo, H.; Norris, M. R.; Ashford, D. L.; Concepcion, J. J.; Brennaman, M. K.; Meyer, T. J. Interfacial Dynamics and Solar Fuel Formation in Dye-Sensitized Photoelectrosynthesis Cells. ChemPhysChem 2012, 13, 2882-2890.

(6) Yu, Z.; Li, F.; Sun, L. Recent Advances in Dye-Sensitized Photoelectrochemical Cells for Solar Hydrogen Production Based on Molecular Components. Energy Environ. Sci. 2015, 8, $760-775$. 
(7) Brennaman, M. K.; Dillon, R. J.; Alibabaei, L.; Gish, M. K.; Dares, C. J.; Ashford, D. L.; House, R. L.; Meyer, G. J.; Papanikolas, J. M.; Meyer, T. J. Finding the Way to Solar Fuels with Dye-Sensitized Photoelectrosynthesis Cells. J. Am. Chem. Soc. 2016, 138 (40), 13085-13102.

(8) Xu, P.; McCool, N. S.; Mallouk, T. E. Water Splitting Dye-Sensitized Solar Cells. Nano Today 2017, 14, 42-58.

(9) Abe, R. Recent Progress on Photocatalytic and Photoelectrochemical Water Splitting under Visible Light Irradiation. J. Photochem. Photobiol. C 2010, 11, 179-209.

(10) Brown, A. M.; Antila, L. J.; Mirmohades, M.; Pullen, S.; Ott, S.; Hammarström, L. Ultrafast Electron Transfer between Dye and Catalyst on a Mesoporous NiO Surface. J. Am. Chem. Soc. 2016, 138, 8060-8063.

(11) Sheibani, E.; Zhang, L.; Liu, P.; Xu, B.; Mijangos, E.; Boschloo, G.; Hagfeldt, A.; Hammarström, L.; Kloo, L.; Tian, H. A Study of Oligothiophene-Acceptor Dyes in P-Type DyeSensitized Solar Cells. RSC Adv. 2016, 18165-18177.

(12) Kamire, R. J.; Majewski, M. B.; Hoffeditz, W. L.; Phelan, B. T.; Farha, O. K.; Hupp, J. T.; Wasielewski, M. R. Photodriven Hydrogen Evolution by Molecular Catalysts Using A12O3Protected Perylene- 3,4-Dicarboximide on NiO Electrodes. Chem. Sci. 2017, 8, 541-549.

(13) Queyriaux, N.; Wahyuono, R. A.; Fize, J.; Gablin, C.; Wächtler, M.; Martinez, E.; Leonard, D.; Dietzek, B.; Artero, V.; Chavarot-Kerlidou, M. Aqueous Photocurrent Measurements Correlated to Ultrafast Electron Transfer Dynamics at Ruthenium Tris DiimineSensitized NiO Photocathodes. J. Phys. Chem. C 2017, 121, 5891-5904. 
(14) Dempsey, J. L.; Esswein, A. J.; Manke, D. R.; Rosenthal, J.; Soper, J. D.; Nocera, D. G. Molecular Chemistry of Consequence to Renewable Energy. Inorg. Chem. 2005, 44, 6879-6892.

(15) Thoi, V. S.; Sun, Y.; Long, J. R.; Chang, C. J. Complexes of Earth-Abundant Metals for Catalytic Electrochemical Hydrogen Generation under Aqueous Conditions. Chem. Soc. Rev. 2013, 42, 2388-2400.

(16) Li, L.; Duan, L.; Wen, F.; Li, C.; Wang, M.; Hagfeldt, A.; Sun, L. Visible Light Driven Hydrogen Production from a Photo-Active Cathode Based on a Molecular Catalyst and Organic Dye-Sensitized P-Type Nanostructured NiO. Chem. Commun. 2012, 48, 988-990.

(17) Li, F.; Fan, K.; Xu, B.; Gabrielsson, E.; Daniel, Q.; Li, L.; Sun, L. Organic DyeSensitized Tandem Photoelectrochemical Cell for Light Driven Water Splitting. J. Am. Chem. Soc. 2015, 137, 9153-9159.

(18) Antila, L. J.; Ghamgosar, P.; Maji, S.; Tian, H.; Ott, S.; Hammarström, L. Dynamics and Photochemical H2 Evolution of Dye-NiO Photocathodes with a Biomimetic FeFe-Catalyst. $A C S$ Energy Lett. 2016, 1 (6), 1106-1111.

(19) Ji, Z.; He, M.; Huang, Z.; Ozkan, U.; Wu, Y. Photostable P-type Dye-Sensitized Photoelectrochemical Cells for Water Reduction. J. Am. Chem. Soc. 2013, 135, 11696-11699.

(20) Kaeffer, N.; Massin, J.; Lebrun, C.; Renault, O.; Chavarot-Kerlidou, M.; Artero, V. Covalent Design for Dye-Sensitized H2-Evolving Photocathodes Based on a Cobalt DiimineDioxime Catalyst. J. Am. Chem. Soc. 2016, 138 (38), 12308-12311. 
(21) Gross, M. A.; Creissen, C. E.; Orchard, K. L.; Reisner, E. Photoelectrochemical Hydrogen Production in Water Using a Layer-by-Layer Assembly of a Ru Dye and Ni Catalyst on NiO. Chem. Sci. 2016, 7, 5537-5546.

(22) Shan, B.; Das, A. K.; Marquard, S.; Farnum, B. H.; Wang, D.; Bullock, R. M.; Meyer, T. J. Photogeneration of Hydrogen from Water by a Robust Dye-Sensitized Photocathode. Energy Environ. Sci. 2016, 9, 3693-3697.

(23) Click, K. A.; Beauchamp, D. R.; Huang, Z.; Chen, W.; Wu, Y. Membrane-Inspired Acidically Stable Dye-Sensitized Photocathode for Solar Fuel Production. J. Am. Chem. Soc. 2016, 138, 1174-1179.

(24) Hoogeveen, D. A.; Fournier, M.; Bonke, S. A.; Fang, X.-Y.; Mozer, A. J.; Mishra, A.; Bäuerle, P.; Simonov, A. N.; Spiccia, L. Photo-Electrocatalytic Hydrogen Generation at DyeSensitised Electrodes Functionalised with a Heterogeneous Metal Catalyst. Electrochim. Acta 2016, 219, 773-780.

(25) Zhao, Y.; Swierk, J. R.; Megiatto, J. D.; Sherman, B.; Youngblood, W. J.; Qin, D.; Lentz, D. M.; Moore, A. L.; Moore, T. A.; Gust, D.; et al. Improving the Efficiency of Water Splitting in Dye-Sensitized Solar Cells by Using a Biomimetic Electron Transfer Mediator. Proc. Natl. Acad. Sci. U. S. A. 2012, 109, 15612-15616.

(26) Tong, L.; Iwase, A.; Nattestad, A.; Bach, U.; Weidelener, M.; Götz, G.; Mishra, A.; Bäuerle, P.; Amal, R.; Wallace, G. G.; et al. Sustained Solar Hydrogen Generation Using a DyeSensitised NiO photocathode/BiVO4 Tandem Photo-Electrochemical Device. Energy Environ. Sci. 2012, 5, 9472-9475. 
(27) Powar, S.; Xiong, D.; Daeneke, T.; Ma, M. T.; Gupta, A.; Lee, G.; Makuta, S.; Tachibana, Y.; Chen, W.; Spiccia, L.; et al. Improved Photovoltages for p-Type Dye-Sensitized Solar Cells Using CuCrO2 Nanoparticles. J. Phys. Chem. C 2014, 118, 16375.

(28) Daeneke, T.; Yu, Z.; Lee, G. P.; Fu, D.; Duffy, N. W.; Makuta, S.; Tachibana, Y.; Spiccia, L.; Mishra, A.; Bäuerle, P.; et al. Dominating Energy Losses in NiO P-Type DyeSensitized Solar Cells. Adv. Energy Mater. 2015, 5 (4), 1401387-1401387.

(29) Krischer, K.; Savinova, E. R. Fundamentals of Electrocatalysis. In Handbook of Heterogeneous Catalysis; Wiley-VCH Verlag GmbH \& Co. KGaA: Weinheim, Germany, 2008; pp 1873-1905.

(30) Gardner, J. M.; Beyler, M.; Karnahl, M.; Tschierlei, S.; Ott, S.; Hammarström, L. LightDriven Electron Transfer between a Photosensitizer and a Proton-Reducing Catalyst CoAdsorbed to NiO. J. Am. Chem. Soc. 2012, 134, 19322-19325.

(31) Wang, Q.; Zakeeruddin, S. M.; Cremer, J.; Bäuerle, P.; Humphry-Baker, R.; Grätzel, M. Cross Surface Ambipolar Charge Percolation in Molecular Triads on Mesoscopic Oxide Films. $J$. Am. Chem. Soc. 2005, 127, 5706-5713.

(32) Anxolabéhère-Mallart, E.; Costentin, C.; Fournier, M.; Nowak, S.; Robert, M.; Savéant, J. M. Boron-Capped Tris(glyoximato) Cobalt Clathrochelate as a Precursor for the Electrodeposition of Nanoparticles Catalyzing H2 Evolution in Water. J. Am. Chem. Soc. 2012, $134,6104-6107$. 
(33) Ghachtouli, S. El; Guillot, R.; Brisset, F.; Aukauloo, A. Cobalt-Based Particles Formed upon Electrocatalytic Hydrogen Production by a Cobalt Pyridine Oxime Complex. ChemSusChem 2013, 6, 2226-2230.

(34) Cherdo, S.; El Ghachtouli, S.; Sircoglou, M.; Brisset, F.; Orio, M.; Aukauloo, A. A Nickel Dimethyl Glyoximato Complex to Form Nickel Based Nanoparticles for Electrocatalytic H 2 Production. Chem. Commun. 2014, 50, 13514-13516.

(35) Anxolabéhère-Mallart, E.; Costentin, C.; Fournier, M.; Robert, M. Cobalt-Bisglyoximato Diphenyl Complex as a Precatalyst for Electrocatalytic H2 Evolution. J. Phys. Chem. C 2014, $118,13377-13381$.

(36) Chen, L.; Chen, G.; Leung, C. F.; Yiu, S. M.; Ko, C. C.; Anxolabéhère-Mallart, E.; Robert, M.; Lau, T. C. Dual Homogeneous and Heterogeneous Pathways in Photo- and Electrocatalytic Hydrogen Evolution with Nickel(II) Catalysts Bearing Tetradentate Macrocyclic Ligands. ACS Catal. 2015, 5, 356-364.

(37) Kaeffer, N.; Morozan, A.; Fize, J.; Martinez, E.; Guetaz, L.; Artero, V. The Dark Side of Molecular Catalysis: Diimine-dioxime Cobalt Complexes Are Not the Actual Hydrogen Evolution Electrocatalyst in Acidic Aqueous Solutions. ACS Catal. 2016, 3727-3737.

(38) Ullman, A. M.; Liu, Y.; Huynh, M.; Bediako, D. K.; Wang, H.; Anderson, B. L.; Powers, D. C.; Breen, J. J.; Abruña, H. D.; Nocera, D. G. Water Oxidation Catalysis by Co(II) Impurities in Co(III)4O4 Cubanes. J. Am. Chem. Soc. 2014, 136, 17681-17688. 
(39) Trotochaud, L.; Young, S. L.; Ranney, J. K.; Boettcher, S. W. Nickel-Iron Oxyhydroxide Oxygen-Evolution Electrocatalysts: The Role of Intentional and Incidental Iron Incorporation. $J$. Am. Chem. Soc. 2014, 136, 6744-6753.

(40) Machado, S. A. S.; Avaca, L. A. Hydrogen Evolution Reaction on Nickel Surfaces Stabilized by H-Absorption. Electrochim. Acta 1994, 39, 1385-1391.

(41) Oshchepkov, A.; Simonov, P.; Cherstiouk, O.; Nazmutdinov, R.; Glukhov, D.; Zaikovskii, V.; Kardash, T.; Kvon, R.; Bonnefont, A.; Simonov, A.; et al. On the Effect of Cu on the Activity of Carbon Supported Ni Nanoparticles for Hydrogen Electrode Reactions in Alkaline Medium. Top. Catal. 2015, 58, 1-12.

(42) Fan, L.; Liu, P. F.; Yan, X.; Gu, L.; Yang, Z. Z.; Yang, H. G.; Qiu, S.; Yao, X. Atomically Isolated Nickel Species Anchored on Graphitized Carbon for Efficient Hydrogen Evolution Electrocatalysis. Nat. Commun. 2016, 7, 10667.

(43) Lu, J.; Xiong, T.; Zhou, W.; Yang, L.; Tang, Z.; Chen, S. Metal Nickel Foam as an Efficient and Stable Electrode for Hydrogen Evolution Reaction in Acidic Electrolyte under Reasonable Overpotentials. ACS Appl. Mater. Interfaces 2016, 8, 5065-5069.

(44) Farmer, J. K.; Gennett, T.; Weaver, M. J. Solvent Effects on the Kinetics of Simple Electrochemical Reactions: Part 1. Comparison of the Behaviour of $\mathrm{Co}(\mathrm{III}) /(\mathrm{II})$ TrisEthylenediammine and Ammine Couples with the Predictions of Dielectric Continuum Theory. J. Electroanal. Chem. Interfacial Electrochem. 1985, 191, 357-366.

(45) Boschloo, G.; Hagfeldt, A. Spectroelectrochemistry of Nanostructured NiO. J. Phys. Chem. B 2001, 105, 3039-3044. 
(46) Marrani, A. G.; Novelli, V.; Sheehan, S.; Dowling, D. P.; Dini, D. Probing the Redox States at the Surface of Electroactive Nanoporous NiO Thin Films. ACS Appl. Mater. Interfaces 2014, 6, 143-152.

(47) Shi, X.; Cai, L.; Ma, M.; Zheng, X.; Park, J. H. General Characterization Methods for Photoelectrochemical Cells for Solar Water Splitting. ChemSusChem 2015, 8, 3192-3203.

(48) Rühle, S.; Greenshtein, M.; Chen, S. G.; Merson, A.; Pizem, H.; Sukenik, C. S.; Cahen, D.; Zaban, A. Molecular Adjustment of the Electronic Properties of Nanoporous Electrodes in Dye-Sensitized Solar Cells. J. Phys. Chem. B 2005, 109, 18907-18913.

(49) Hod, I.; Tachan, Z.; Shalom, M.; Zaban, A. Characterization and Control of the Electronic Properties of a NiO Based Dye Sensitized Photocathode. Phys. Chem. Chem. Phys. 2013, 15, 6339-6343.

(50) Zhang, L.; Favereau, L.; Farré, Y.; Mijangos, E.; Pellegrin, Y.; Blart, E.; Odobel, F.; Hammarström, L. Ultrafast and Slow Charge Recombination Dynamics of Diketopyrrolopyrrole-NiO Dye Sensitized Solar Cells. Phys. Chem. Chem. Phys. Phys. Chem. Chem. Phys 2016, 18, 18515-18527.

(51) Smeigh, A. L.; Le Pleux, L.; Fortage, J.; Pellegrin, Y.; Blart, E.; Odobel, F.; Hammarström, L. Ultrafast Recombination for NiO Sensitized With a Series of Perylene Imide Sensitizers Exhibiting Marcus Normal Behaviour. Chem. Commun. 2012, 48, 678-680.

(52) D’Amario, L.; Antila, L. J.; Pettersson Rimgard, B.; Boschloo, G.; Hammarström, L. Kinetic Evidence of Two Pathways for Charge Recombination in NiO-Based Dye-Sensitized Solar Cells. J. Phys. Chem. Lett. 2015, 6, 779-783. 
(53) Swierk, J. R.; McCool, N. S.; Saunders, T. P.; Barber, G. D.; Strayer, M. E.; VargasBarbosa, N. M.; Mallouk, T. E. Photovoltage Effects of Sintered IrO2 Nanoparticle Catalysts in Water-Splitting Dye-Sensitized Photoelectrochemical Cells. J. Phys. Chem. C 2014, 118, 1704617053.

(54) Michaux, K. E.; Gambardella, A. A.; Alibabaei, L.; Ashford, D. L.; Sherman, B. D.; Binstead, R. A.; Meyer, T. J.; Murray, R. W. Visible Photoelectrochemical Water Splitting Based on a Ru(II) Polypyridyl Chromophore and Iridium Oxide Nanoparticle Catalyst. J. Phys. Chem. C 2015, 119, 17023-17027.

(55) Trasatti, S. Work Function, Electronegativity, and Electrochemical Behaviour of Metals. J. Electroanal. Chem. Interfacial Electrochem. 1972, 39, 163-184.

(56) Gajek, A.; Zakroczymski, T. Long-Lasting Hydrogen Evolution on and Hydrogen Entry into Iron in an Aqueous Solution. J. Electroanal. Chem. 2005, 578, 171-182.

(57) Palmer, D. A.; Bénézeth, P.; Xiao, C.; Wesolowski, D. J.; Anovitz, L. M. Solubility Measurements of Crystalline $\mathrm{NiO}$ in Aqueous Solution as a Function of Temperature and pH. $J$. Solution Chem. 2011, 40, 680-702.

(58) Huang, L. F.; Hutchison, M. J.; Santucci, R. J.; Scully, J. R.; Rondinelli, J. M. Improved Electrochemical Phase Diagrams from Theory and Experiment: The Ni-Water System and Its Complex Compounds. J. Phys. Chem. C 2017, 121, 9782-9789.

(59) Ito, S.; Miura, H.; Uchida, S.; Takata, M.; Sumioka, K.; Liska, P.; Comte, P.; Péchy, P.; Grätzel, M. High-Conversion-Efficiency Organic Dye-Sensitized Solar Cells with a Novel Indoline Dye. Chem. Commun. 2008, 128, 5194. 
(60) Daeneke, T.; Kwon, T.-H.; Holmes, A. B.; Duffy, N. W.; Bach, U.; Spiccia, L. HighEfficiency Dye-Sensitized Solar Cells with Ferrocene-Based Electrolytes. Nat. Chem. 2011, 3, 213-217.

(61) Favereau, L.; Warnan, J.; Pellegrin, Y.; Blart, E.; Boujtita, M.; Jacquemin, D.; Odobel, F. Diketopyrrolopyrrole Derivatives for Efficient NiO-Based Dye-Sensitized Solar Cells. Chem. Commun. 2013, 49, 8018.

(62) Perera, I. R.; Gupta, A.; Xiang, W.; Daeneke, T.; Bach, U.; Evans, R. A.; Ohlin, C. A.; Spiccia, L. Introducing Manganese Complexes as Redox Mediators for Dye-Sensitized Solar Cells. Phys. Chem. Chem. Phys. 2014, 16, 12021.

(63) Perera, I. R.; Daeneke, T.; Makuta, S.; Yu, Z.; Tachibana, Y.; Mishra, A.; Bäuerle, P.; Ohlin, C. A.; Bach, U.; Spiccia, L. Application of the tris(acetylacetonato)iron(III)/(II) Redox Couple in P-Type Dye-Sensitized Solar Cells. Angew. Chem. Int. Ed. 2015, 54, 3758-3762.

(64) Salvatori, P.; Marotta, G.; Cinti, A.; Anselmi, C.; Mosconi, E.; Angelis, F. De. Supramolecular Interactions of Chenodeoxycholic Acid Increase the Efficiency of DyeSensitized Solar Cells Based on a Cobalt Electrolyte. J. Phys. Chem. C 2013, 117, 3874-3887.

(65) Adler, D.; Feinleib, J. Electrical and Optical Properties of Narrow-Band Materials. Phys. Rev. B 1970, 2, 3112-3134.

(66) May, T. W.; Wiedmeyer, R. H.; Chaudhary-Webb, M.; Paschal, D. C.; Elliott, W. C.; Hopkins, H. P.; Ghazi, a M.; Ting, B. C.; Romieu, I.; Vicente, O.; et al. A Table of Polyatomic Interferences in ICP-MS. At. Spectrosc. 1998, 19, 150-155. 